\title{
Assessment of veterinary services in central Ethiopia: A case study in Ada'a District of Oromia Region, Ethiopia
}

\author{
Tariku Jibat ${ }^{*}$, Ashenafi Mengistu ${ }^{1}$, Kidane Girmay ${ }^{1}$ \\ ${ }^{1}$ Addis Ababa University, College of Veterinary Medicine and Agriculture, P.O.Box 34, Debrezeit, \\ Ethiopia. \\ *Corresponding author: E- mail: jibattariku@gmail.com
}

\begin{abstract}
This study was conducted to identify actors, their roles, competences and main constraints of veterinary service delivery system in Ada'a district of the Oromia Regional State, Ethiopia. Questionnaire, focus group discussions, key informant interviews and desk review were conducted to gather primary and secondary data. This assessment revealed that the district obtains veterinary services mainly from three sectors: public sector, private sector and NGOs. The public sector serves $62 \%$, $56 \%$ and $45 \%$ of clinical treatment, vaccination and drug sales, respectively. The private veterinary service contributes $40 \%, 5 \%$ and $43 \%$ of clinical treatments, vaccination and veterinary drug sales, respectively. The Donkey sanctuary and SPANA-Ethiopia are major NGOs that handle equine clinical cases and vaccination. Inadequate budget, logistic problems, shortage of manpower and fewer working days were found to be the main causes for the weakness of government veterinary services, and black-market drug dealers were found to be challengers associated with the private sector.
\end{abstract}

Keywords: Ada'a district, Drug, Private, Public, Vaccine, Veterinary service http://dx.doi.org/10.4314/evj.v19i2.9

\section{Introduction}

Agriculture is the basis of Ethiopia's economy and is the most important economic sector in terms of generation of foreign currency. The sector is the primary source of livelihood for more than $85 \%$ of Ethiopian rural households who practice subsistence crop and livestock production.

The livestock sector in Ethiopia contributes 12 and 33\% of the total and agricultural Gross Domestic Product (GDP), respectively, and provides livelihood for $65 \%$ of the population. The sector also accounts for $12-15 \%$ of total export earnings, the second in order of importance (Ayele Assegid et al. 2003; Halderman, 2005). Animals provide highly nutritious foods, and provide 
draught power, transport, manure, and hides and skins (IPST, 2004). To ameliorate the development constraints and realize the benefits from the huge but untapped livestock resource, efforts have been made in various aspects to develop the livestock sector in Ethiopia. These efforts include the provision of input and services such as veterinary services, breed improvement, feed resources development, research, extension services and development, finance and marketing (Azage Berhanu et al. 2006).

Animal disease is one of the major bottlenecks of animal productivity in central Ethiopia including Adaáliben district (Wudu Kelay et al. 2008). Ada'a district is the second populous district in East Shoa Zone with majority of rural population living on animal agriculture. Thus, this study was conducted with the objectives of identification of actors, their roles and competences in the veterinary service delivery system in the study area and to identify the main constraints of veterinary service delivery system in the study area.

\section{Materials and Methods}

\section{Study site and population}

Ada'a district of the Oromia Regional State is found about $47 \mathrm{~km}$ south east of Addis Ababa, the capital city of Ethiopia and it is located at $9^{\circ} 36^{\prime \prime} \mathrm{N}$ and $9^{\circ} 36^{\prime \prime} \mathrm{E}$. The study involved livestock owners, veterinarians, public veterinary clinics, NGOs (non-governmental organizations), private veterinary pharmacy owners, veterinary drug importers and distributors and district and federal veterinary service officers.

\section{Sampling technique and sample size determination}

A multi stage simple random sampling procedure was employed to select farmer associations and households in the study area. The district was first stratified in to urban, peri-urban and rural areas based on their proximity to Debre Zeit town. Three kebeles were selected from the three areas of the district purposely based on the distance from the veterinary clinics and accessibility of drug stores or pharmacies. From each kebele 8-12 household heads were selected randomly for the group discussion. The sample size for the questionnaire survey was determined according to Arsham's (2007) formula, considering a standard error of $5 \%$. Accordingly, the total sample size computed was 100 households. Thus, for the questionnaire survey 40,30 and 30 respondents were selected from the urban, peri-urban and rural areas, respectively. 


\section{Data collection}

Questionnaire survey, focus group discussions, key informant interviews and desk review were conducted to gather primary and secondary data. A detailed questionnaire was designed and farmers were interviewed in an attempt to generate baseline information related to veterinary service delivery, livestock production with particular emphasis on major livestock health problems; major livestock diseases; lost animals due to disease and major measures taken by farmers. Focus group discussions were conducted at each selected PA using a semi-structured questioner where the participants are free to discuss on the issue and report their final consensus according to principle of participatory rural appraisal (Uddin and Anjuman 2013). Key informant interviews were conducted using checklist involving people participating in veterinary service delivery, veterinary service users and the government officers at district, regional and federal levels. Results of previous studies, guidelines, manuals, policies, regulations and other literatures were reviewed to assess status of current veterinary service, drug administration and licensing, surveillance and reporting systems across the country and especially of the districts of Oromia Region. Routine activities and outbreak reporting formats developed at different veterinary offices were also thoroughly assessed.

\section{Data analysis}

Data collected was stored in Microsoft office Excel 2007 and analyzed by descriptive statistic using SPSS (Version 17). Qualitative data collected through focused group discussion, interviews of veterinary service providers and government policy document was subjected to narrative analysis.

\section{Results}

\section{Means of livelihoods}

The major sources of livelihood in the rural and peri-urban areas were mixed crop livestock production and cropping (Table 1). This mixed crop-livestock livestock production system is an interdependent system where livestock serves as traction power for tilling the land and animals manure serves as fertilizer while crop residue serve as animal feed. 
Table 1: Means of livelihoods for farmers in Ada'a district.

\begin{tabular}{lllll}
\hline Means of Livelihood & Urban & Peri urban & Rural & P value \\
\hline Mixed farming & 2.50 & 93.33 & 96.67 & $0.000^{*}$ \\
Crop rearing & 0 & 6.67 & 3.33 & 0.000 \\
Dairy Farming & 52.50 & 0 & 0 & 0.000 \\
Employment & 27.50 & 0 & 0 & 0.000 \\
Petty trade & 17.50 & 0 & 0 & 0.000 \\
\hline
\end{tabular}

*Significant at $\mathrm{P}<0.05$.

\section{Livestock keeping constraints}

According to the focus group discussion, livestock disease, grazing land and feed shortage were the major livestock keeping constraints identified by the respondents in rural and peri-urban areas in descending order. However, 90\% of the respondents of the urban area have ranked feed shortage followed by livestock disease as major livestock keeping constraints.

\section{Profile of veterinary service providers}

The questionnaire survey as well as group discussions show that public veterinary service, private veterinarians, traditional healers and NGOs mainly Donkey sanctuary and SPANA-Ethiopia are the main source of veterinary services in the District. Based on our findings, veterinary service providers in the area were classified in to public, private and third sector (Ada'a Dairy Cooperative, Donkey Sanctuary and SPANA-Ethiopia).

This study revealed that the public veterinary clinical service delivered by Ada'a District Agricultural and Rural Development Office contributes for the district's $62 \%$ clinical treatment, $56 \%$ of vaccination service and $45 \%$ of drug sales. The Faculty of Veterinary Medicine of Addis Ababa University is another public veterinary service provider accounting for the provision of $28 \%$ of the clinical service and $27 \%$ of the drugs sales.

Private organizations and individuals providing veterinary services in the District include veterinary drugs shops and mobile clinics providing full time and part time services. Private practitioners serve on call basis for $40 \%$ of the clinical cases treatment, $5 \%$ of the vaccination services and $43 \%$ of the drug sales. Part time veterinary service providers mainly act in the urban area and serve $11 \%$ of clinical cases treatments, $2 \%$ vaccination and $9 \%$ of drug sales. The informal drug dealers in the open market mainly sell their drugs 
to the rural and peri-urban parts of the district which accounts for $53 \%$ of the respondents. Members of the Ada'a Dairy Cooperative get access to veterinary service from the cooperatives full time veterinarians. This accounts for $12.5 \%$ of the clinical veterinary services, $7.5 \%$ of the vaccination and $10 \%$ of the drug sale in the urban area.

The Donkey sanctuary gives clinical services contributing about 16.67 and $6.67 \%$ of the service in peri-urban and rural areas, respectively while SPANA covers $7.5 \%$ of clinical treatments and vaccination in the urban areas. In addition, SPANA provides harnessing materials and training to farmers and other stakeholders without any service charge.

\section{Constraints of veterinary services}

The public veterinary service is constrained by availability of drug (78\%), vaccine (81\%) and veterinarians in clinic especially in the weekend and holidays in which emergency cases are obliged calling private veterinarians. Distance from vaccine distribution centers and lack of working schedule on dates of vaccination were also identified as major constraints of the veterinary service. Response from different actors of the veterinary service on their perception about the major constraints of veterinary service is mentioned in table 2 .

Table 2: Constraints in the provision of veterinary services.

\begin{tabular}{llllc}
\hline Constraints & \multicolumn{3}{l}{ Sub System } \\
\cline { 2 - 5 } & $\begin{array}{l}\text { Urban } \\
(\mathbf{\%})\end{array}$ & $\begin{array}{l}\text { Peri-urban } \\
\mathbf{( \% )}\end{array}$ & $\begin{array}{l}\text { Rural } \\
\mathbf{( \% )}\end{array}$ & P-value \\
\hline Vaccine & & & $0.000^{*}$ \\
$\quad$ Lack of service provider & 22.50 & 50 & 00 & \\
$\quad$ Lack of vaccine & 77.50 & 26.67 & 60.00 & \\
$\quad$ Expensive (Vaccine) & 00 & 10.00 & 30 & \\
Distance from clinic & & & & $0.002^{*}$ \\
Within 2-4km & 100 & 36.67 & 43.33 & \\
$>=5$ km & 00 & 63.33 & 56.67 & \\
Drug Shortage & 75 & 66.67 & 93.33 & $0.000^{*}$ \\
Weekend closed clinic & 5 & 76.67 & 86.67 & $0.000^{*}$ \\
Shortage of skilled manpower in the clinic & 42.5 & 53.33 & 76.67 & $0.002^{*}$ \\
\hline
\end{tabular}

*Statically significant $(\mathrm{P}<0.05)$ **highly significant 


\section{Evaluation of veterinary service providers by clients}

Respondents were asked to show their priorities according to the relative timeliness, effectiveness and affordability of the veterinary service providers. Accordingly, respondents put the public veterinary service (WoARD and SVM) as their first choice for its effectiveness and affordability compared to the private veterinary service in their area. In addition they have high trust in the drug used by public veterinary service providers. Clients blame the public veterinary service providers for lack of timeliness and rank them behind the private veterinary service providers. The "open air clinic" at the Faculty Veterinary Medicine of Addis Ababa University was regarded as giving service with the highest quality and low cost. In the assessment, the respondents preferred the private veterinary service for their timeliness and availability even for door to door service. The Ada'a Dairy Cooperative members choose put the veterinary service provided by their own cooperative second to the public veterinary service in terms of costliness but it was ranked behind the private veterinary service providers in terms of timeliness. The Ada'a Dairy Cooperative members prefer the service provided by the cooperative for its service provision at home or farm level.

\section{Discussion}

Livestock keeping is repeatedly reported the major source of livelihood of people living in the rural and peri-urban of central Ethiopia. for example by Dagnachew (Dagnachew Seyum, 2004) mentioning animal diseases to be responsible for lowered productivity. Our study revealed the identified the actors and constraints related to of the animal health service.

The finding of this study include 1) The actors identified in the veterinary service deliver clinical treatment, drug sales and vaccination services 2) Shortage of veterinary drug, closed during weekends and public holidays and distance are the main constraints of the public veterinary service 3 ) The informal drug dealer in the open market mainly sells their drug mainly to the rural and peri-urban areas as there are loose inspections and few competitors 4) The public veterinary service was chosen as first choice for effectiveness and costliness compared to private veterinary service as the cost of clinical case treatment service and cost of drug are subsidized by the government and 5) private services providers are good at timeliness in case of emergency and door to door service. 
The actors identified to deliver clinical treatment, drug sales and vaccination services are similar to the ones reported from Ethio-Kenyan border area by Bayissa and Bereda (Bayissa and Bereda, 2009) except the involvement of community animal health workers (CAHWs) as veterinarians are not motivated to work in such remote areas. The public veterinary service is the main veterinary service provider in the peri-urban and rural areas of the District while, the urban areas receives veterinary service mainly from private veterinary service providers Girma (Girma, 2008). The activities of the public veterinary services was very limited because of inadequate budget, logistic problems, lack of basic veterinary equipment, and shortage of trained manpower and low capacity of veterinary section as opposed to recommendations of OIE (OIE 2010). This study shows that the private veterinary service is helping that livestock producer to access the required service. For example, some of the participants of the study believe that dairy cooperative also contribute to vaccination, treatment and drug sales for prevention and control of different diseases mainly for its members in the urban though constrained by poor service delivery and shortage of manpower in the public veterinary services. However, we could not access information on the level of involvement of such cooperation sin the veterinary service. Such experiences are also reported from other countries like Switzerland (Rüsch and Kihm, 2003).

Shortage of veterinary drug, closed during weekends and public holidays and distance are the main constraints of the public veterinary service. There is high significance difference between the urban, peri-urban and rural subsystem in the proximity towards the clinics which are concentrated in urban areas. The finding opposes with Marabelli (Marabelli, 2003) who noted that the role of veterinary medicine is to help rural communities to remain on their land, protecting the health of their animals and the safety of the animal products that are so essential to the income of the farmers.

The public veterinary service was chosen as first choice for effectiveness and costliness compared to private veterinary service as the cost of clinical case treatment service and cost of drug are subsidized by the government (Girma, 2008). While the private services providers are good at timeliness in case of emergency and door to door service. However, the cost of private veterinary service is the most expensive and the effectiveness is ranked last. This was related with them is use of drug, expired drug and under dosing for increased sales size. This is similar to the finding of Girma (2008) and Tefera (2008) who remarked that private veterinary service providers ranked first for timeliness but last in the effectiveness and cost of services. 
Furthermore, the government has to set strict regulations for that has to be provided so as to improve definitive diagnosis and timely veterinary services provision, public veterinary clinics working hours should be increased with appropriate incentive and the supply of veterinary drugs has to be increased to improve rational use of veterinary drug and reduce people looking for blackmarketed drugs, the government has to minimize subsidizing the veterinary services and drugs to promote the participation of private practitioners in the sector and encourage veterinary practitioners to involve in provision of mobile services instead of retailing veterinary drug.

\section{Conclusion}

In Ada'a District there are options for veterinary service with ranges of effectiveness, timeliness and costliness in veterinary services. Shortage of veterinary drugs, vaccine, logistics, and working hours in the public veterinary clinics and black market-drug are the main constraints of veterinary service in the district. Therefore, the authors would like to recommend public veterinary services need to be up to the standard recommended and equipped with all the necessary manpower, operational budget and logistic facilities to come to a self-sustaining business.

\section{References}

Ayele, S., et al. 2003. Livestock marketing in Ethiopia: A review of structure, performance and development initiatives. Socio-economics and Policy Research Working Paper 52. ILRI (International Livestock Research Institute), Nairobi, Kenya. pp 35.

Azage, T., et al. 2006. Input supply system and services for Market oriented Livestock Production in Ethiopia. Paper presented at the 14th annual conference of the Ethiopian Society for Annual Production (ESAP) on: Institutional arrangements and challenges in market oriented livestock agriculture in Ethiopia. September 5-7, 2006. Addis Ababa, Ethiopia.

Bayissa, B. and A. Bereda 2009. Assessment of Veterinary Service Delivery, livestock Disease Reporting, Surveillance Systems and Prevention and Control Measures Across Ethiopia/Kenya Border Enhanced Livelihood in Southern Ethiopia (ELSE) Project CIFA Ethiopia/CARE Ethiopia, December, 2009. pp. 1-29.

Dagnachew, S. 2004. Epidemiology of Bovine Trypanosomosis in the Abbay basin areas of northwest Ethiopia. MSc Thesis, Addis Ababa University, faculty of veterinary medicine, Debre Zeit, Ethiopia. 
Girma, A. 2008. Dairy Service Delivery in Debre Zeit Milkshed of Ada'a District, Central Ethiopia: Analyzing Options to Development Pluralistic Service Delivery in the Dairy Sector. MSc Thesis, Haramaya University, Ethiopia.

Halderman, M. 2005)]. The Political Economy of Pro-Poor Livestock Policy-making in Ethiopia. Working Paper. PPLPI, FAO, Rome, Italy, xiii+59 pp.

Marabelli, R. 2003. The role of official Veterinary Services in dealing with new social challenges: animal health and protection, food safety, and the environment. Rev. sci. tech. Off. int. Epiz., 2003, 22 (2), 363-371.

OIE 2010. Tool for the evaluation of Performance of Veterinary Services OIE-PVS Tool PVS Evaluation Report, Botswana, April 2010, Pp. 23-130.

Rüsch, P. and U. Kihm 2003]. The federal system of Veterinary Services in Switzerland. Rev.sci. tech. Off. int. Epiz., 2003, 22, 423-432.

Tefera, E. 2008. The Role of Dairy Cooperatives in Stimulating Innovation and Market Oriented Smallholders Development: The Case of Ada'a Dairy Cooperative, Central Ethiopia. MSc. Thesis, Haramaya University.

Uddin, I. and N. Anjuman 2013. Participatory rural appraisa approaches; An overview and exemplary application of focus group discussion in climate change adaptation and mitigation strategies. M.N. Int. J. Agril. Res. Innov. and Tech. 3 (2), 72-78.

Wudu, T., et al. 2008. Calf morbidity and mortality in smallholder dairy farms in Ada'a Liben district of Oromia, Ethiopia. Trop Anim Health Prod. 40 (5), 369-376. DOI 10.1007/s11250-007-9104-3. 